\title{
A comparison approach to explain risks related to $x$-ray imaging for scoliosis
}

\author{
N Pace ${ }^{1 *}$, L Ricci $^{2}$ \\ From 9th International Conference on Conservative Management of Spinal Deformities - SOSORT 2012 \\ Annual Meeting \\ Milan, Italy. 10-12 May 2012
}

\section{Background}

$\mathrm{X}$-ray imaging is frequently used as a diagnostic approach for scoliosis in children and adolescents. X-ray procedures are justified only when expected benefits exceed related risks. While benefits are well known to physicians, radiological risk awareness can be vague, impeding an optimal communication with patients' parents, and possibly leading to discomfort and anxiety.

\section{Aim}

To suggest a risk comparison approach for better communicating the radiological risks related to X-ray investigation of scoliosis.

\section{Methods}

Starting point of the analysis is the Linear Non Threshold (LNT) assumption for radiation stochastic effect [1]: for effective doses (E) below $100 \mathrm{mSv}$, the probability of future stochastic damage is linearly related to $\mathrm{E}$. This allows to add E from different sources to calculate a cumulative risk of health detriment. Data coming from literature were gathered to determine the average $\mathrm{E}$ delivered during X-ray investigation of scoliosis. Subsequently, the major natural sources of radiation, namely cosmic rays, $40 \mathrm{~K}, 222 \mathrm{Rn}$ and other radionuclides, were considered. The average E due to these natural sources was compared with $\mathrm{E}$ due to the imaging of the vertebral column.

\section{Results}

For a single standard scoliosis radiographic examination [2], E ranges from 0.2 to $0.35 \mathrm{mSv}$ [3]. Therefore, the LNT assumption can be used. The main natural radiation

BIOtech - Interdepartmental Center on Biomedical Technologies, Università di Trento, Trento, Italy

Full list of author information is available at the end of the article source is $222 \mathrm{Rn}$, which on average accounts for $1.2 \mathrm{mSv} /$ y (range $0.2+/-10 \mathrm{mSv} / \mathrm{y})$. Cosmic rays $(0.4 \mathrm{mSv} / \mathrm{y}$, range $0.3+/-1.0)$ and terrestrial gamma rays from other radionuclides $(0.8 \mathrm{mSv} / \mathrm{y}$, range $0.3+/-1.4)$ are additional sources of natural radiation. Moreover, flying from Europe to North America accounts for 0.03-0.05 mSv, and because of the unavoidable presence of $40 \mathrm{~K}$, consuming 1,000 bananas, or carrots, accounts for approx. $0.1 \mathrm{mSv}$. Overall, $65 \%$ of the world population is expected to be exposed to an annual $\mathrm{E}$ between 1 and $3 \mathrm{mSv}$ (average $2.4 \mathrm{mSv})[1]$.

\section{Conclusions}

Data coming from literature show how, on average, the effective annual dose coming from natural sources greatly exceeds the effective dose due to $x$-ray imaging for scoliosis. This information can play a key role in the relationship between physicians and patients.

\section{Author details}

${ }^{1}$ BIOtech - Interdepartmental Center on Biomedical Technologies, Università di Trento, Trento, Italy. ${ }^{2}$ Dipartimento di Fisica, Università di Trento, Trento, Italy.

\section{Published: 3 June 2013}

\section{References}

1. Radiation UNSCotEoA: Sources And Effects Of lonizing Radiation Report to the General Assembly, with scientific annexes. 2000, 1, vol. Report.

2. Radiology TACo: ACRSPR Practice Guideline for the Performance of Radiography for Scoliosis in Children.[http://www.acr.org/ /media/ FD620650A1B346579E89909FB3BFBB45.pdf], (2009 revised).

3. Mogaadi M, BO L, Hammou A: Effective dose for scoliosis patients undergoing full spine radiography, Radiation Protection Dosimetry. 2011, 17.

doi:10.1186/1748-7161-8-S1-037

Cite this article as: Pace and Ricci: A comparison approach to explain risks related to $\mathrm{x}$-ray imaging for scoliosis. Scoliosis 2013 8(Suppl 1):O37.

\section{Ciomed Central}

(C) 2013 Pace and Ricci; licensee BioMed Central Ltd. This is an Open Access article distributed under the terms of the Creative Commons Attribution License (http://creativecommons.org/licenses/by/2.0), which permits unrestricted use, distribution, and reproduction in any medium, provided the original work is properly cited. 